\title{
Chapter 4 \\ Public Lives, Private Water: Female Ready-Made Garment Factory Workers in Peri-Urban Bangladesh
}

\author{
Deepa Joshi, Sadika Haque, Kamrun Nahar, Shahinur Tania, Jasber Singh, \\ and Tina Wallace
}

\subsection{Introduction}

Bangladesh is South Asia's fastest emerging economy with a Gross Domestic Product growth rate of $7.11 \%$ (World Bank, 2017a). This is a significant achievement for a predominantly low income country. The Ready Made Garment (RMG) industry, the country's largest export sector, is a key contributor to this economic growth trajectory and is also the country's largest employer of women. Of the over 4.2 million people working in the RMG industry, around $80 \%$ workers are women (CPD, 2018). It would not be incorrect to say that female RMG workers are key drivers of the Bangladeshi economy (see Rahman \& Siddiqui, 2015).

How has this employment changed the everyday lives and livelihoods of this essentially female work force? While researchers acknowledge the formidable challenges for Bangladeshi women working in the RMG industry (Feldman, 2009; Kabeer, 1999, 2000, 2001; Kabeer \& Mahmud, 2004a, b), there are nonetheless claims that the mass employment of women in the RMG industry has led to significant gender gains (World Economic Forum, 2018, 2019). It is argued that entrenched

\author{
D. Joshi $(\bowtie)$ \\ International Water Management Institute (IWMI), Colombo, Sri Lanka \\ e-mail: deepa.joshi@cgiar.org \\ $\mathrm{S}$. Haque $\cdot \mathrm{S}$. Tania \\ Bangladesh Agricultural University, Mymensingh, Bangladesh \\ K. Nahar \\ University of Manitoba, Manitoba, Canada \\ J. Singh \\ Coventry University, Coventry, UK \\ e-mail: ac5866@coventry.ac.uk \\ T. Wallace \\ Oxford University, Oxford, UK
}


gender barriers, in particular cultural restrictions on women's physical and social mobility and ideological perceptions that women cannot or should not earn income have been overcome (Kabeer, 2001). RMG women workers in Bangladesh are also said to "have a (relative) autonomy $[\ldots]$ a greater bargaining power $[\ldots]$ expanded choices and gains in power" (Hossain, 2012, p. 3) and "an enhanced ability to formulate choice[s] and act upon those choices" (Souplet-Wilson, 2014, p.1). It is no surprise then that the RMG industry in Bangladesh is widely claimed to have empowered Bangladeshi women (World Bank, 2008, 2017b). The World Economic Forum identifies Bangladesh as the most gender equal country in South Asia and as having surpassed developed economies as well in furthering gender equality (see World Economic Forum, 2018, 2020).

However, the RMG industry in Bangladesh is also infamous globally for two major events: a fire breakout in the Tazreen factory in Ashulia District in peri-urban Dhaka in 2012, where 117 workers were confirmed dead and over 200 were injured; and the collapse of the Rana Plaza building complex in 2013 in another peri-urban suburb, Savar, with a death toll of 1134 and 2500 injured. Much has been written about these incidents and also about subsequent efforts to promote and ensure "safety-at-work" initiatives.

The political economy of the RMG industry in Bangladesh makes for a perfect case to understand how globalization intersects with gender. Of course, it depends on how these links are analysed or rather, who is analysing these intersects. The World Bank's World Development Report (2012, p.xxi) notes that "forces such as trade openness $[\ldots]$ spread of cheaper communication and technologies $[\ldots]$ connect women to markets and economic opportunities [...] reshaping attitudes and norms about gender relations, and encouraging countries to promote gender equality." This analysis explains how Bangladesh ranks at 50 among 149 countries in the World Economic Forum's 2020 Global Gender Gap index report, where a key indicator is economic empowerment.

Feminist researchers critique these measures, as well as the narrative that asserts that any wage employment for women translates into their empowerment. Ruth Pearson (2007, p.117) explains that trade liberalization has reiterated rather than reversed gender inequalities: by making poor women the cheap workers of globalized value chains, even as these women combine the burdens of poorly paid productive work with unpaid domestic work responsibilities, ensuring that "being exploited by capital" is virtually the fate of poor women in today's global economy.

In 2018, Shafiqur Rehman wrote of the imbalances in relation to gender equality and the RMG economy in Bangladesh, ${ }^{1}$ highlighting two key issues. First, Rehman argued that the work opportunities for poor women in the RMG industry are poorly paid and "labour-intensive", with a "lack of learning and upgrading of jobs" where workers have "short shelf-lives" and are "unceremoniously terminated (with no

\footnotetext{
${ }^{1}$ https://www.dhakatribune.com/opinion/op-ed/2018/12/24/imbalance-in-economy-and-politics-ofbangladesh
} 
post-work benefits) after the end of the productive years" at work. In other words, this is not "decent work" and does not offer "living wages" and meet other decent work conditions (see International Labour Organization et al., 2016). Secondly, because "more than $85 \%$ of the total exports" in Bangladesh "is just from the RMG industry" and because the export industry runs the country's "miraculous' economic growth $[\ldots .$.$] the industry creates a narrow business elite that can easily col-$ lude with the government for preferential treatment". In a situation where the nation's GDP is buoyed by the RMG industry, critiques of the economic and/or environmental externalities of the industry have made little dent on what happens on the ground.

In this chapter, we discuss how poor women in Bangladesh not only service the RMG labour market on unfavourable terms and in challenging work contexts, but also function in a social and cultural setting where gendered norms dictate that, even as women work outside the house, they are still fully responsible for unpaid care and domestic work. This happens in a context where, while the women pay almost a third of their wages for small rooms in crowded tenements, sharing poorly maintained and overtly crowded toilets and bathrooms, they are unable to question the landlords on the conditions of their rents and living conditions, especially also water availability, use and access.

We understand women's empowerment as their ability and agency for "transforming power relations" at scale, so as to "define change for themselves and negotiate change" individually and collectively, at scale and on their terms (Sharma et al., 2007, p.11). This conceptual understanding of empowerment defines that "the material and non-material dimensions of all our lives are inextricably intertwined" and therefore it is not possible to segregate the economic, social and political dimensions of empowerment (ibid, p.12). Our findings mirror what has been reported elsewhere-an overwhelming "feminization of responsibility [of both domestic and productive work] and/or obligation" resulting in "a growing unevenness in male and female inputs to household economies" in situations where "women and girls have limited power to (re)negotiate this intensified reliance" on their time, labour and lives (Chant, 2016, p. 3-4). Building on what we observe through a gender-waterwork focus, we critique what is positioned and claimed as economic development and women's (economic) empowerment.

In the sections below, we first explain our approach of a critical participatory ethnography. This methodology section is followed by a conceptual overview of the political economy of the RMG sector and how this impacts water inequalities. We then discuss in detail the research findings-where we analyse the meanings and experiences of privatized waters and the public lives of women RMG workers. This section is then followed by a final discussion and conclusion. 


\subsection{Methodology: Our Framing of Their Stories. Ethnography in an Unequal World}

Informed by a feminist political economy framework and guided by critical participatory research methods, our aim was to facilitate some 30 female RMG workers working and living in Bhadam to reflect on their everyday lives in the public and private spaces where they work and live. Bhadam (Fig. 4.1), the location for this research, a small settlement (locally known as mouza) in Gazipur District in Dhaka Division, is one of many such peri-urban settlements, where RMG workers live by the hundreds along the Dhaka-Gazipur highway. Gazipur, which used to be part wetland, part paddy fields on the banks of the Turag River, is now the heavily industrialized heartland of the RMG sector.



Fig. 4.1 The study area 
Our focus was to enable women working in the RMG factories to voice their experiences, hopes and challenges in a context not driven by an outsider research agenda to extract data. Thus, while this research project was essentially about water, we did not emphasise this in our engagements and discussions with women RMG workers. If water was a key concern to the women we spoke to and interacted with, it would, we anticipated, emerge as a key topic of discussion. And indeed, water did emerge as a key challenge, with other issues of gender-power disparities and masculinities, both inside and outside the home, in private and public domains.

Despite the fact that, in Bhadam, the factories and the one-room accommodations the workers rent are not too far away, getting an insight into people's lives by "deeply hanging out" (Geertz, 1998) was immensely challenging. Most of our interactions with the female RMG workers happened in the small, cramped rooms where they lived with their families, on Fridays, the day off for RMG factory work. However, as we noted, factory work also occasionally happens round the clock to meet specific seasonal demands of customers in the North. The key challenges were the unavailability of time to meet and speak, and the lack of space for discussions. The living quarters - rooms divided by tin shutters-were in some cases just behind the factory walls. The hum of generators and other factory machinery made it difficult to speak to or hear each other-the public work place seamlessly flowing into the domestic space, which is anything but private.

Two of our researchers (and co-authors) lived in Bhadam in such rented rooms for over 8 months and experienced first-hand some of the challenges faced by RMG women workers. They were evicted from their rental accommodation three times, because the male landlords decided in each case to oust them arbitrarily, without explanation or notice to leave. We thus came to understand how RMG workers and their families experience the power and authority of male landlords. While the rent workers pay is almost a third of their wages for such living arrangements, they are completely unable to challenge forced eviction or rent, water and electricity charges, water rationing, poorly maintained toilets and bathrooms conditions, and the overall exercise of control of space (Fig. 4.2).

In this challenging environment, we met and spoke to over 30 female RMG workers as well as several male members of their family-individually and sometimes in a group, over a period of a year. Twelve of these women reflected on their lives and their work with a local street theatre group called Bot Tala (under the Banyan tree). These reflections were later translated into a theatre play, which has been co-produced with these women into a video. ${ }^{2}$ Overall, the stories of the 30 women were stories of deep poverty, lack of choice, distress migration, challenging living and working conditions, hard tedious work at home and at the factory, tiredness, low status in the community and, of course, an endless battle to secure enough water for all household purposes.

It took significant time to win the trust of these 12 women-many were shy, lonely and also wary of sharing their life experiences with others. The gradual

\footnotetext{
${ }^{2}$ For the video, see https://youtu.be/7GxkzNWRVlM
} 


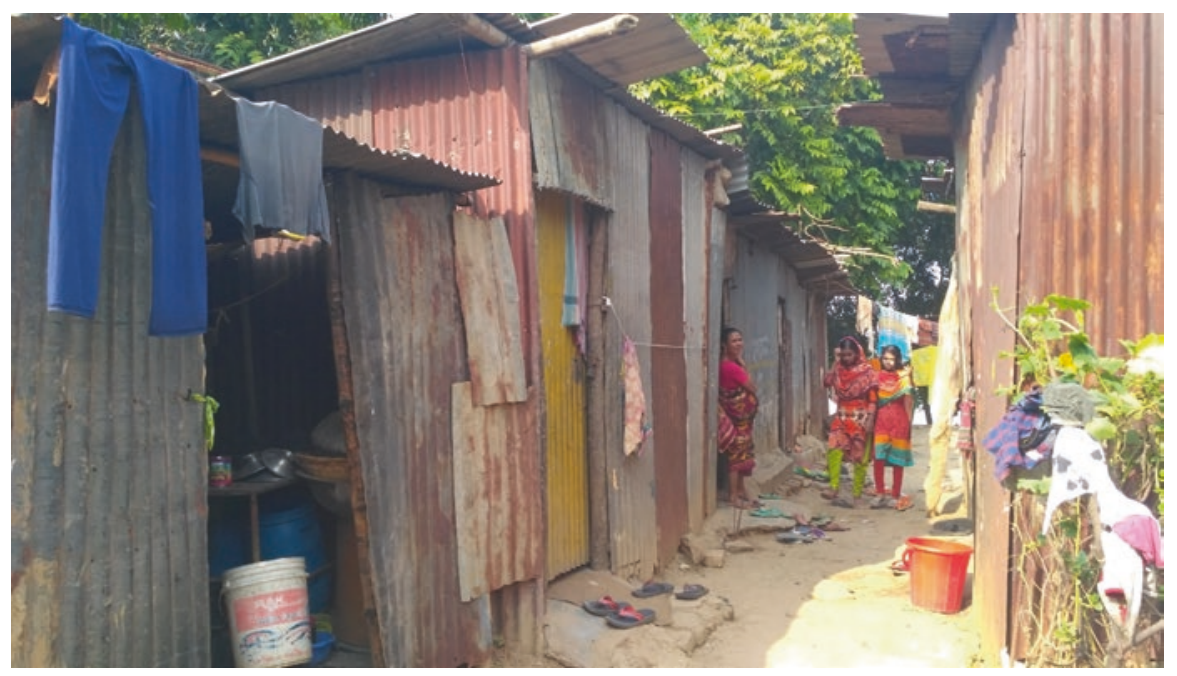

Fig. 4.2 Housing of 20 families of female garment industry workers. (Photo Sadika Haque)

nature of interactions and the space to discuss and share everyday lived experiences at their pace were key in engaging with them. In trying to be mindful of the tensions and contradictions of power and privilege in doing research, our project moved slowly. Our co-authors often took on the role of surrogate care givers and educators of the children of the women we wanted to speak with. During the short-term, mission-driven purpose of our engagement we were glad to be useful in some ways. For many literate RMG workers, the fact that they were raising their children into illiteracy - there are no public schools in Bhadam-was of deep concern. We tried, not always successfully, to not make compulsions or demands on their engagement. There was a lot shared over time, much of what they cared about deeply is not possible to fully detail in this chapter: their childhood memories; experiences of migration; compelling poverty in the rural areas; the pain of separation from children left behind in the villages or all day while at work; aggression and abuse by men at home and men at work; physical and emotional challenges in their marital relations due to, among other issues, time stress; their isolation from wider community support; problems with not having access to schools and healthcare; having no recreational spaces or time to relax — and much more. The focus in this chapter is on their experiences as urban workers in the RMG industry and as working wives living in urban slums where housing is costly and overcrowded, where water supply is inadequate and unilaterally determined by male landlords, where the gross pollution of surface and groundwater and the overall environment go unregulated, and where the lack of time impacts everything that is expected socially of a good, virtuous and desirable wife and mother.

As researchers working in Bangladesh for a long time, we have often grappled with the politics of "researching" poverty and gender (Joshi et al., 2011). Poor women in Bangladesh may lack many things, but research attention is something 
that they are often disproportionately subject to. Many researchers, including us, claim to be "doing" participatory research, guided by "a feminist ethnographic methodology, which gives careful attention to diverse experiences and voices by heeding the constraints, opportunities and challenges in women's lives, and looks for thick description, specific data and stories that are profoundly gendered and relevant to the context" (Sultana et al., 2013, p.5). And yet, working on issues of gender, water and poverty in Bangladesh, we have been acutely aware of the tensions and contradictions between a scientific obsession with data-also called the "mission-creep of scientific knowledge processes" (see Wakeford \& SanchezRodriguez, 2018) — and the purpose, value and relevance of such data for those who are "researched". While participatory, ethnographic methods may deliver nuanced, granular insights into complex ground realities, to assume that such research can or will shift the praxis of social injustices (Palmer, 2001) is deliberately naïve. We argue here that "deeply hanging out" with the marginalized does not easily qualify as being inherently political or participatory. Escobar $(2007,2015,2016)$ argues, that, regardless of the focus on the sub-altern, if the goal is to contribute to established Eurocentric knowledge systems - then, no matter how critical the methods and approaches, they do not necessarily qualify as being epistemologically transformative. Transformative, transdisciplinary research requires "changing not just the content but the very terms of the conversation" (Escobar, 2007, p. 191).

It is, therefore, important to acknowledge that, while project funding enabled us, a group of female and male researchers from Northern and Southern institutions, to try and deeply hang out with female ready-made garment (RMG) factory workers in peri-urban Bangladesh, nonetheless, despite our best intentions of being participatory, the findings we discuss here can only qualify as "hybrid research-occasionally but not always facilitating 'participants' to make sense of [and challenge] their real situations and contexts" (Wakeford \& Rodriquez, 2018, p.26).

\subsection{Public Water Privatized}

Before discussing in further detail the intersection of paid work and gendered domestic water responsibilities of RMG women workers, it is important to understand how the political economy of the RMG industry in Bangladesh has shaped the political economy of water. As we discussed above, the RMG industry in Bangladesh is acclaimed for accelerating productivity and the nation's GDP as well as the empowerment of the industry's women workers. And just as the everyday lived experiences of the women workers at work and at home are silenced in outsider expert claims of (their) empowerment, the environmental degradation as an outcome of industrialization and growth is also grossly overlooked.

Hossain and Samad Khan (2017) stress that the industry's ecological footprint is alarming. While the industry's entire value chain is "highly water intensive", what is a more immediate concern is the unregulated mining of groundwater by the industry (at no costs) and the release of untreated effluents containing several 
hazardous dyes and heavy metals. The RMG sector, including textile dyeing, is classified officially as a highly polluting "Red Category" Industry under the 1995 Environmental Conservation Act (ibid; 438). The industry is responsible for an average of " $86.15 \%$ of total grey water footprint for the country" (ibid; 438, 447). Ironically, as of May 2019 Bangladesh also reported the highest number of Leadership in Energy and Environmental Design (LEED)-certified garment factories globally: 24 according to the United States Green Building Council (USGBC). ${ }^{3}$ However, this number, compared to the absolute numbers of large and small RMG factories identified in total as 4621 in $2018-19$ by the Bangladesh Garment Manufacturers and Exporters Association, ${ }^{4}$ explains why, as Sakamoto et al. (2019, p.1) note, the industry's supposedly "great success comes with great environmental deterioration".

Ignoring the overall "agricultural water consumption for cotton farming", various textile industries "in and around Dhaka may consume as much groundwater as goes to all of Dhaka's residents" (Hossain \& Samad Khan 2017, p.437). More importantly, the water pollution has far-reaching impacts: "vegetable and fruit samples collected from around Savar, Dhamrai, and Tongi (other peri-urban locations where the RMG workers live) show the presence of textile dyes, industrial wastes and effluents containing heavy metals [...] all regularly released into the already heavily polluted river water, which is still being used for irrigating paddy and vegetable (spinach, tomato and cauliflower) fields in industrial areas in Gazipur and Keraniganj" (ibid, p.6). The RMG workers we met in Bhadam knew that the Turag River is too polluted to even wash clothes, but they can do little to protect themselves from the pollution in the water they drink and the food they eat.

The study region, including Bhadam, is not served by any water supply provided by the state. Land- and home-owning residents of Bhadam, who are landlords to large numbers of migrant RMG workers, make personal investments to draw groundwater for domestic use from tubewells by means of submersible pumps. There are no fees (to the landlords) for using groundwater, but there are significant costs for buying, setting up and maintaining the water pumps, and the electricity to run the pumps. This explains why water availability is a contentious issue between the landlords (usually men) and tenants. At all times and regardless of the rental arrangements, landlords decide the timing and frequency of running the submersible pumps. Women RMG workers are mostly getting back from work at a time of the evening (7-8 p.m.) when the water storage tanks have run dry. While the women need water for drinking and cooking, there is no option but to wait till the next refill or to request the landlord or his family members to extend a favour. These requests are often not taken well and create an enormous anxiety each day. None of the RMG workers in Bhadam own land or have their own homes. The lack of political capital as migrants, the lack of land, homes, financial capital or other assets of their own

\footnotetext{
${ }^{3}$ https://www.thedailystar.net/business/news/bangladesh-has-highest-number-greengarment-factories-1749016

${ }^{4}$ http://www.bgmea.com.bd/home/pages/TradeInformation
} 
means that the migrant RMG workers cannot sink water pumps. It is worrying that migrant workers lack these resources, regardless of the length of stay in these areas and work in the factories. In sum, regardless of how long they have migrated, they are perpetually migrants, lacking political, social and financial capital.

In a rare, one-off incident in a nearby settlement, a group of migrant workers living in what was essentially a slum-like situation in Gazipur, had tried petitioning local authorities and had been allotted a submersible pump from the local office of the City Corporation. Several people in the community lobbied with higher-ranking government officials in the same institution and managed to take back the pump. Some form of politico-legal identity might have restored some voice but, as we learnt, most RMG workers also do not aspire for a local politico-administrative status in the peri-urban fringes where they live. Not a single respondent we met had officially registered as local resident (i.e. an eligible voter). When we asked why, every single person, male and female migrant RMG worker, said that this was because they want to go back home one day. It is also true that most workers, especially women, have neither the resources nor the time to pursue these changes.

However, even if this politico-legal barrier was negotiated, it is not possible for the migrant workers to put together the financial resources to access water. Often it takes three to four less affluent landlords to pool resources to invest in one submersible pump. As the wife of a landlord explained:

We, three house owners, are the joint owners of one pump. When the pump became dysfunctional for a week, we were all, including the tenant workers, collecting water from the nearby mosque. As my husband could not manage money to repair it, I have sold my ornaments and given him Tk. 45,000 (USD 525). Each of the owners is contributing the same amount to set up a new water pump.

Focusing on water, Sultana et al. (2013) have written that, since the 1980s, neoliberal economics has framed the country's politics, in the process also determining the institutional mandate of the water sector, as well as notions of citizenship and rights to basic services. While policy defines water as a public good, in practice water is a private commodity in Dhaka city and the surrounding peri-urban areas. The rate of growth and expansion of the city undoubtedly constrains the city's (Dhaka) Water Supply and Sewerage Authority (DWASA), which as it appears is also fighting external agendas of corporatization (i.e. privatization) introduced as "water reforms" by agencies like the Asian Development Bank (ADB). In Dhaka, DWASA has, however, resisted privatization, even though the ADB continues to emphasize "a timebound action plan for private sector participation" (Asian Development Bank, 2017).

Interestingly, the ADB report, titled, "The Dhaka Water Services Turnaround" notes that DWASA executives and engineers were initially resistant to delivering water to urban poor slum dwellers, arguing that this would "affect the pressure in other areas of the system and hurt paying customers" and would "turn those water thieves (the urban poor in slums) into regular customers" (ibid; p.32). A change in attitude was apparently possible because the ADB was able to engage local NGOs to take fiscal responsibilities and became intermediaries between "the utility and the communities" (ibid; p.34). We spell out these issues here because, unlike in urban 
slums, there are no legally informal areas, i.e. slums, here. These are well organised migrant-tenant settlements. We also found no local NGOs looking into issues of exclusion and marginality in Bhadam or in the neighbouring areas. As we understand, organisations like UNICEF are engaged in improving WASH services in factories; and NGOs like Action Aid work with RMG workers, including women, to support and extend worker rights. However, both were not known or recognised by the people we met and spoke to in Bhadam- the women RMG workers, their families, local residents (i.e. landlords) or those who had managerial positions in the factories. This is hardly surprising: Bhadam lies some six kilometers away from the main road, and one cuts through several such settlements before one arrives here.

It is important to add here that the Constitution of Bangladesh abides by and acknowledges the obligation of the nation state to ensure that basic necessities of life such as food, clothing, shelter, education and medical care are accessible to all citizens. Water, however, is not listed as one of the basic necessities of life. This oversight is perhaps explained by the fact that the 1999 National Policy for Safe Water Supply and Sanitation, declares water as owned and controlled by the state and to be managed by public, private and/or community institutions, as deemed appropriate by the state (Ministry of Water Resources, 1999). Similarly, the Government of Bangladesh's (GoB) 2005 Poverty Reduction Strategic Papers (PRSP) and Bangladesh's Water Act 2010 speak of the citizen's right to water, but not the state's obligation to supply safe water. It is for all these reasons, that DWASA is commended for its efforts to resist privatization and persist as a public water institution (Transnational Institute, , 2004). However, as we discussed above, public water institutions are not necessarily inclusive.

More recent shifts in Bangladesh' water and sanitation policy aim to target the hard to reach areas and people, i.e. the poorest and most disadvantaged. This turnaround in policy is spelt out in the 2010 Sector Development Program document which, in contrast to earlier policies and guidelines, states the obligation of the national government to provide safe drinking water to all its citizens. The SDP document also outlines the need for equitable subsidies and for local contextual issues to inform water development decisions, including the consideration of social values, cultural practices and technical appropriateness of the design and development of water services and infrastructure. In principle, these policies could inform the ambitiously planned transition of the DWASA to WASA, a 23-year master plan - the 2035 Greater Dhaka Water Supply and Sanitation Plan. Among other issues, this plan aims to ensure water supply and sewerage to the currently unserved peri-urban regions of Savar, Tongi, Keraniganj, Purbachal and Gazipur. It is unclear how these plans will take into account the challenging problems of skewed landlord-tenant relations, which we describe below. Further, what matters is not just provision of water infrastructure and services but, as Sultana et al. (2013, p.2) have argued, also recognizing that "place-based politics determine [...] rights and injustices" in the socio-political "fabric". In other words, there cannot be equitable water provision without full rights of citizenship (ibid). And as we discuss below, gender plays prominently in the experience of place, space, identity, citizenship, water infrastructure and governance. 


\subsection{Living in Bhadam: Women in Masculine Spaces and Places}

In the late 1990s, the RMG industry moved from the urban fringes of Dhaka into surrounding rural landscapes, which are today the peri-urban industrial zones including areas like Gazipur, Savar and Narayanganj. The rapid development of the industry coincided with a rampant construction of rental accommodations for migrant workers from impoverished rural areas with little opportunities for income. Depending on the season, monsoon or drier months, it takes about an hour or less to navigate the seven kilometres from the main Gazipur-Dhaka highway to Bhadam. The tarred roads of the highway rapidly give way to small roads, which are essentially soil embankments on either side of wetlands and agricultural lands. It is extremely difficult to drive and even more precarious to walk these roads, as well as the streets in Bhadam in the monsoon, when wet clay soils become slippery pathways.

Bhadam as a place is unnervingly masculine: tall cemented factories fenced by tall barbed wires, manned (pun intended) by male guards round the clock. Heavy duty trucks and warehouse transport vehicles traverse through and often block the narrow temporary roads connecting the factories to the main road. Nearby are clusters of settlements where the migrant workers and Bhadam's more settled residents live-interspersed with a string of small provision stores and tea stalls, where men hang out in their spare time. The only institutional infrastructure other than the factories are mosques - and a significant number of minarets which dot the neighbourhood call out prayers every Friday, and five times a day. The Friday sermons, broadcast through loudspeakers, are particularly interesting. Often when we were there, there was a warning to all, but especially to women, of the impacts of "modernity". Women were reminded to be virtuous, chaste and abiding to their husbands.

\subsubsection{At Work}

Although RMG work is presented as offering economic as well as social opportunities for women, the experiences of the women we spoke to were different. Distress migration is what pushes women from rural villages into the RMG factories. There were stories of crushing poverty, crises of debt, ill health or death in the family, or sometimes womens' decision to elope with lovers, against the wishes of their families. RMG work is relatively easy to find for women but it provides no contracts, no terms and conditions of work, no scope for growth and advancement, and work tenure is not permanent. RMG workers are obviously poor and perceived as desperate. Lacking other means of a livelihood they are looked down upon by the local (non-migrant) community in Bhadam. Local women do not work in the RMG factories. A few resident local men work in the factories, but always in better paid, less laborious jobs. Even though most of the migrant women working in the RMG 
factories say that factory work, even with all its limitations, is still better than other informal jobs in the area, their everyday experiences are rarely positive. Of the 30 women we spoke with, only two spoke of the workplace as being welcoming, as having presented opportunities for a better life and friendships with other women. For most women, the balancing of poorly paid, laborious work in the factories and domestic housework is enormously challenging.

On a daily basis, if women reach the factory gates late even by a few minutes, male guards can disallow their entry, resulting in loss of work and the equivalent wage for that day. Women have to negotiate for leave, if they or other family members are sick; and often have to struggle to ask for toilet breaks during working hours. The insecurity of their work, their inescapable poverty makes them perpetually scared of being docked without pay for being absent without proper permission. Their relationships with the male guards and male supervisors, who are key liaison persons with the administration, is skewed. There are many stories of manipulative behavior: the more beautiful and young(er) one is, the easier it is to get a job, and a less tiring one. Women and girls considered not so beautiful, or too old, risk not being hired at all —and multiple favours are demanded by the men in power. The sheer numerical strength of women workers has unfortunately not enabled them to challenge the masculine hierarchies at work. Work conditions are changing but not significantly improving for the women: there are now improved WASH facilities inside many factories, but women have little time to use them. Wages have increased but net income or savings have not. There are trade and labour unions and regulations, but these are almost entirely comprised of men. It is still difficult to negotiate leave, there is no maternity leave, working hours are still long, work is often arduous and indiscriminate terminations continue-and the list goes on. Even though women do earn an income, this has not enabled them to challenge the conditions of their work.

During the work day, women get an hour's break for lunch (Fig. 4.3). This is when they queue for the toilets or access drinking water, both of which they avoid during work hours because of the risks of not meeting production targets. Those who live nearby sometimes rush home to check on the children, clean, wash and eat before rushing back to work. The rush and competition continues when they return home in the evening - to cook, clean, wash and be the wives and mothers they were not during the working day. Their insecurity and fear of breaking rules came through in most of our conversations, as did the relentless pressure of targets, trying to fit everything into the day, and the sheer lack of time. Some do not drink to avoid the need for a toilet break. They often talked of intense tiredness and the repetitive nature of the work amidst dust and dirt. They also spoke of often having to accept compulsory overtime work, for which they are paid additionally in most cases.

In December 2018, the average salary increased from BDT 5300 (USD 63) to around 8000 BDT (USD 93). Although this was a significant rise, this is only half of what labour and trade unions had been demanding as living wages (BDT 16,000 or USD 190). The current salary equals just over three USD for over $8 \mathrm{~h}$ of work per day, 6 days a week. Almost a third of the wages is spent on rent for a small one-room house. Often, as soon as the salaries increased, the house rents also increased 


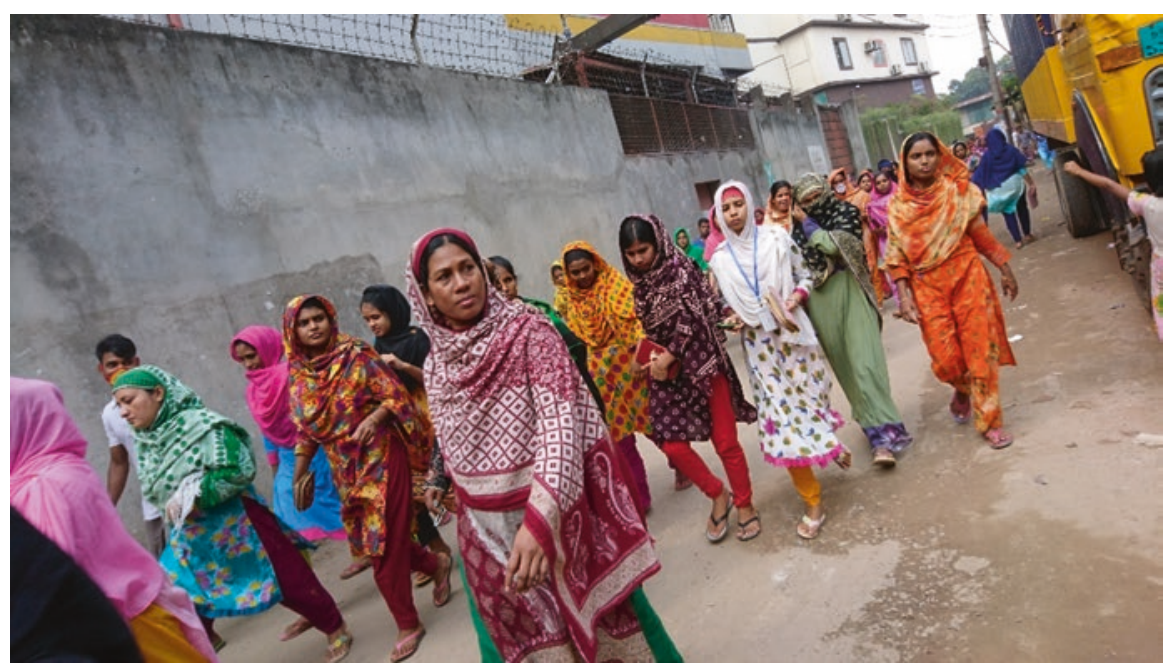

Fig. 4.3 Factory workers going for lunch. (Photo Sadika Haque)

proportionately. We know this not only from the women, but also because the rent for the room we were renting ourselves increased proportionate to the increase in wages during this time.

The conditions of work described by the women do not convey a sense of empowerment. This does not imply there are no benefits or gains from paid work. Most women express a sense of pleasure and pride in being able to earn an income, contributing [primarily] to the household upkeep and sending money home for the children left behind. Yet very few women can determine how to spend the income they earn or spend money on themselves; while everyone speaks of trying to save money to return home, very few are able to do so.

\subsubsection{At Home}

In Bhadam, the type of rental accommodation and the quality and quantity of water for domestic use and WASH facilities are influenced by what workers can pay for a room (varies from BDT 2000-5000). Regardless of what they pay and therefore where they live, there are no contracts and no mutually agreed terms and conditions of rent, while eviction is an everyday threat. The landlord unilaterally determines rental conditions; there are no norms, no rules, no regulation of who pays what and why. Additionally, there are intermittent cuts in the water supply, random extra changes and constant demands of sexual favours and/or threats. The landlord-tenant relationship is a key indicator of disproportionate power exercised by the male landlord, regardless of the length of stay in the community of RMG workers. 
It was reported that owning a fridge, a TV, having more children, a larger family, or occasional guests can result in increases of the rent amount. Often any additional costs of repairs, maintenance, and high electricity bills are passed on to the vulnerable tenants. Notice to leave can be given at any time. When we (co-authors) were evicted, it was immediate; the landlords gave us less than an hour to leave. The RMG workers, especially single women, live with this threat of evictions every day. Space, place and basic infrastructure and services are not issues that tenants can voice opinions about. The demand for rental accommodation is high and there is no incentive for landlords to be reflexive, though a few migrant men, including husbands of RMG workers, protest these injustices.

The overcrowding in the living arrangement is shocking: sometimes over 100 people live in 20 or 25 rooms, equipped with two toilets, two taps, one or two bathrooms and a limited number of shared kitchen spaces and cooking stoves. The toilets and bathrooms are not segregated by gender and the lack of privacy is burdensome and shaming, especially for women. Lack of water due to this intense overcrowding is common. Many women start their day at 3 to 4 am in the morning to wash and use the toilets and kitchens before the long queues build up later in the morning. Many of the stories shared were related to the lack of time to access the facilities, the shortages of water at peak times, how broken taps can be left unfixed for days on end, the lack of privacy and self-respect, and extremely dirty toilets and washrooms that they share with the other tenants. The women also routinely talked about how hard it is to get to work in time, especially during the rains, with slippery roads and the overspill of waste water on the pathways.

There is little space for migrant RMG residents in general, but particularly for the women, to influence decisions around water. Much of the video produced focused on the distress caused by the shortages of drinking water, the refusal of landlords to turn on the pumps to meet daily water needs, river water that is polluted and unusable, and the long queues for the toilet and bathrooms, which is especially problematic for women who need to reach the factories in time. Landlords include water in the rent, but they limit water availability by closely monitoring the use of the water pumps. Attempts by women tenants to approach male landlords to request additional water (switching the pump on) is looked upon by his family as a way of these women to make sexual advances to a desirable, powerful male. During the research we noted that fairly straightforward requests by these women often result in aggressive responses and/or physical violence by the wives and extended families of the landlord. RMG women workers who speak up or argue are seen as opinionated and immoral, and routinely harassed and even beaten by the wives of the landlords or the landlords themselves. A female RMG worker aged 15 explains:

one Friday, when I was at home, I noticed that there was no water in the tank. At the very moment, the son of the house owner, aged 17 was passing by. I asked him to request his mother to switch the pump on. Immediately afterwards, the wife of the house owner came out and started beating me with her sandal, expressing anger on how I had dared to speak to her son about water. 'Why did you do this? You should not speak with my son. Tell me if you need anything'. 
Mimi, who is young, beautiful, deserted by her husband and childless is precisely the sort of woman that the wives of landlords fear and the landlord himself and his male managers see as easily accessible for sexual harassment.

\subsubsection{Gendered Household Water Burdens: Not Negotiable}

Despite working long days of 8-10 h, 6 days a week, when women return home they resume the role and burdens of being mothers, wives, daughters and/or daughtersin-law, even when they are primary household income earners. Managing domestic tasks is squarely women's responsibility. Only three out of 30 women said their husbands help them in any way. One of this group of three said:

Sometimes if my husband comes earlier from office than I and is hungry, he will cook some rice, collect some water and sometimes even wait to eat, till I arrive". Another said: "my husband always helps in all the work, we cook together, cut fish, wash clothes together. When we were in the village, my husband also tried to help me but my mother-in-law did not allow him to help. This has changed after coming to Dhaka: here, he can help me as much as he wants.

And yet, she is still, "very afraid of him", of annoying him, of losing this good fortune that so many others around her do not have. The majority of women felt they had no way to challenge their traditional gendered responsibilities in the home. For most women, the situation at home is unbelievably challenging:

I had to do overtime work at the factory yesterday night and came home at about $2 \mathrm{am}$. On getting home exhausted, I found our room in a terrible mess. I cannot ever imagine that he will cook food for me. I found that he had not even washed his lungi (lower body wrap for men) after taking a bath, even though I knew he was at home since the afternoon. I washed it late at night, because he needs it for work the next day and if it is not clean or dry, he will beat me. Actually I cannot express my feelings at that moment. I just blame my fate for such a husband.

\section{Another woman said:}

I have been suffering for a few days with fever and cold. With this physical condition, after getting up, I do all the work, I have washed the bathroom and taken a bath. Today is Friday. My husband had brought fish and chicken from the market in the morning and gone out. $\mathrm{He}$ has not returned yet-it is 12 noon. I have just finished cooking this for lunch, even though, I have not had anything to eat since I woke up. Despite being ill, I have to do all the work, he doesn't help me in household work. I cannot ask for his help even though he is a good husband. He does not beat me.

For another, "getting help from my husband is beyond my imagination. My husband has another wife and sometimes he is coming to me just to get some money".

On Fridays, women may get up a little later, but face domestic work that has accumulated over a week: cleaning their single-roomed homes, cooking lunch, washing and drying clothes, bathing children and cleaning the toilets and bathrooms. While women are barely seen in the streets, men congregate in tea-stalls and barber shops on Fridays and after work hours in the evening to get a shave or head 
massage, to smoke and sit by the sides of the road, and in local mosques on the call of prayers (Azaan).

Most of the 30 women we met and spoke to at length reported handing over their entire wages to their husbands or at the very least giving them some "pocket money". Many men increasingly threaten that, if the women cannot pay more "pocket money", they will be abandoned for women who can and will pay more. Some of these men even tell their wives: "I will come back-when you can pay me more than what I am given now [by another woman]". We heard countless stories of men both young and old, addicted to narcotic substances, appropriating their wives' earnings through aggression and violence. At home, at work and in the community, the women continue to be at the mercy of men; and despite the crowded social environment at work and in the community, they are deeply isolated and alone.

From the women, we also heard of an ominous practice, which we term, the "floating husband" syndrome. The social need for a husband has resulted in some women (whose husbands have deserted them) investing in men, who float around different households, staying a few days, collecting some money, being "looked after" with good food, rest, maybe more. In the eyes of the wider community, the women have a husband, who is, as they say, "working and living elsewhere". Even in such situations the women usually do not "leave" their men. The deep-rooted culture of women's inequality means they still cannot easily live alone or abandon their husbands. The skewed relations result in several women being abandoned by their husbands, having husbands who spend their hard earned income on drugs, gambling or other women.

Our findings reveal that women holding paid work have not really been able to negotiate the sharing of domestic burdens with men. Instead the domestic water responsibilities of washing, cleaning, cooking are readily handed over to elderly mothers and younger (not yet working) daughters. Young girls from age five to six onwards routinely assist with the household work and rearing younger siblings (Fig. 4.4). As many women explain there is not much else to do in Bhadam. There are no schools, public or private; open spaces for play need to be found in the narrow roads where trucks ply day in and out, or in the polluted, toxic backyards of factories and the banks of the Turag River.

Further, gendered identities, roles, responsibilities, privileges and barriers have hardly changed among the RMG (male and female) workers we met in Bhadam. Gendered relationships are increasingly frayed, with men expecting and demanding their wives - and occasionally mothers and sisters - to provide both domestic comforts and material privileges. Just like at work, at home too coercive masculinities are the ways used to control the women. Even though so many women report of physical violence and aggression, very few feel able to stand up to or counter this behavior.

Heath and Mobarak $(2014,2015)$ noted a lowering of fertility rates-i.e. reduced rates of child birth among paid RMG workers - and considered this to be an indicator of their empowerment. Such measures fail to take into account the fact, that there are no easily accessible or reliable medical or health services in Bhadam. The timepressed women RMG workers have a harrowing time dealing with their personal 


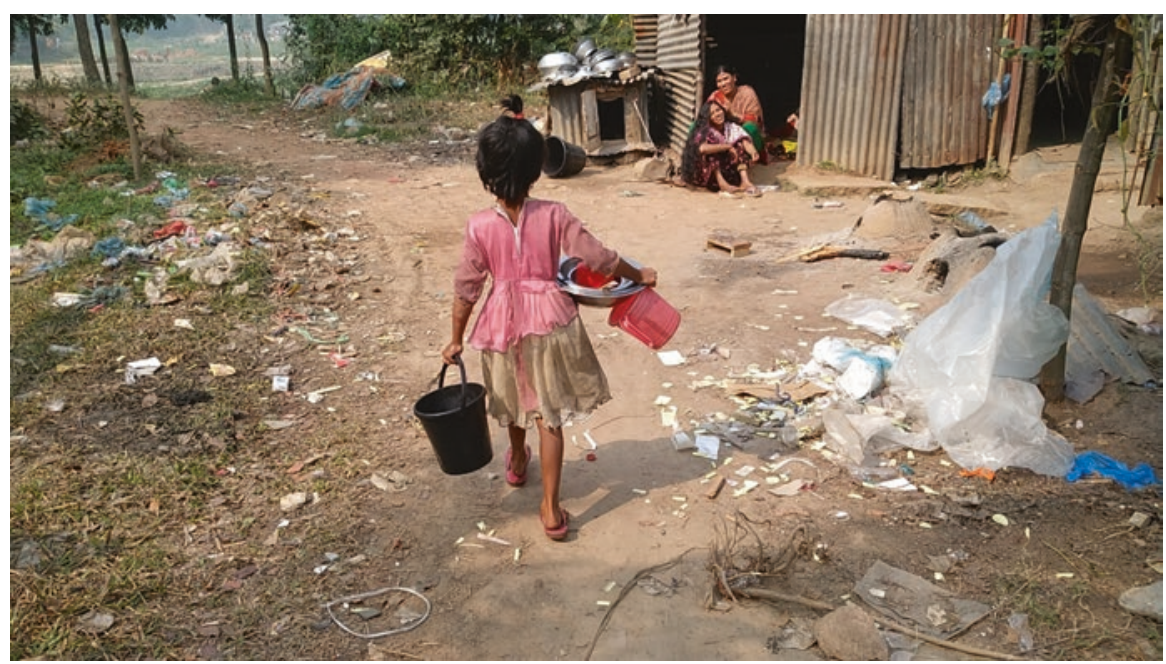

Fig. 4.4 Girl on her way to a water source. (Photo Sadika Haque)

health situations and their children's health. They also seem to spend very little on their own health. It is very likely that women RMG workers make for a significant proportion of the recent surge in numbers of unsafe abortions in Bangladesh. According to the Guttmacher Institute, in 2014, an estimated 384,000 women suffered complications from clandestine abortions, $1 / 3$ of this number did not get any post-abortion care that they needed, and $2 / 3$ were treated later for complications from unsafe abortions (Hossain et al., 2017). ${ }^{5}$

The stories shared by the women showed a limited power of women and girls to (re)negotiate an intensified reliance on their time, labour, bodies and lives, as has been reported elsewhere by Chant (2016). And, despite the claims of their empowerment, women have greatly subdued expectations of the relations with the men they share their lives and incomes with, of better work conditions and, last but not least, appropriate, affordable water and sanitation infrastructure and services.

\subsection{Conclusion}

In the claims made for women's paid work being an indication of their empowerment, there is mention of increased mobility, autonomy, voice and negotiating abilities among women RMG workers. The stories told by the women we met are different from these narratives. While women are indeed mobile and out of the house in public spaces, this often comes at disproportional costs to their everyday lives and is also deeply damaging at a personal level.

\footnotetext{
${ }^{5}$ https://www.guttmacher.org/infographic/2017/complications-clandestine-abortion-bangladesh
} 
Most of what we saw and heard when living alongside the women RMG workers in Bhadam, spoke of a pervasive masculinity. There are multiple interpretations and definitions of masculinity. Here we refer to masculinity as identities associated with men in traditionally patriarchal cultures and practices, where male privilege, "aggrandisement and power" within and outside the household is the norm (Chant, 1999, 199). On the other hand, we also interpret masculinity as cultures, practices and values where the privilege and power of a few over others is not uncommon in social, economic and political interrelations where "accumulation and patriarchy" go hand in hand (see Mies, 1986).

It is indeed true that millions of Bangladeshi women are employed. But is this a conscious choice exercised by them or is it a conscious compromise as a result of a precarity that the women have little control over? Do the wages and income from paid RMG work empower women or do they further fuel a culture of capitalism and patriarchy? The decisions that women RMG workers make in continuing work in the factories or staying married with their husbands or the relations they establish with other men as a form of social protection or even staying in Bhadam in the rooms they rent, seem to indicate complexities that cannot be easily explained as choice, freedom or empowerment.

Nussbaum's (2000) capabilities approach allows paying attention to multiple dimensions of disempowerment-economic, social and emotional unfreedoms at work and home and the inability or the conscious choice to not act on these tyrannies. When viewed from such a perspective, it is obvious that the Bangladeshi RMG female workers have enormous "human capabilities": to be, to cope and, in this case, also to fuel the Bangladeshi economy. Unfortunately, there has been little reciprocity to these women by the country, the industry, and by men in their households and the community. Deep-rooted exclusionary behaviors and attitudes are prevalent, not only among the husbands of the female RMG workers and the male landlords of Bhadam, but also persisting institutionally at scale. In the face of such pervasive, structural exclusions, it is ironic to say that poor women in poorly paid work in challenging living and work situations and contexts are empowered. Empowering women RMG workers will require structural changes in the political economy of work as well and water. The question we ask here is, whether a policy focus on inclusion and the expansion of WASH services in peri-urban areas, such as the 2035 Plan, might resolve the challenges we discussed above. We do not feel very optimistic that deep-rooted problems of water insecurity and exclusions will be resolved so easily, especially because multiple factors disable both male and female RMG workers from navigating and engaging in public spaces where water management and governance decisions are made by a few powerful men in places like Bhadam.

It is also worrying that new water policy directives are informed by the rather outdated Women in Development (WID) narrative. Put into practice, this would require women in local communities to take the lead in voluntarily managing water supply infrastructure and services in addition to their domestic burdens and paid labour in the factories. The assumption that women can and must take leadership roles in collecting water fees for communal systems and convincing everyone (in the community) to pay is made, because, "Women are (supposedly) better at 
convincing than men..." (ADB, 2017; 36). In an overall context where economic and environmental injustices and inequalities are a given, where there is an institutional failure to (deliver) public water, and where women's inequality and lack of power is entrenched in everyday social and economic interrelations, it is surely naïve to assume paid work and a small income will transform deep gendered inequalities. When the structural conditions and environments—or what Nussbaum (2000) calls "functioning capabilities" are disabling, individual employment of women alone does not ensure empowerment. In fact, Nussbaum (ibid, 220) argues that in such contexts, women became, as also seen in Bhadam, "mere instruments to the ends of others, as reproducers, caregivers [...] agents of a family's general prosperity".

It is precisely in such contexts, that Isha Ray's (2016) argument for gender transformative investments is critical. According to her, this means not leaving the strategic and fundamental human need for water to ambiguous or "voluntary" institutional arrangements including "market forces or non-governmental actors" or to the women themselves, who work full-time. The problem of ignoring the economic value of women's domestic unpaid work has been well argued (UN Women, 2016-2017). However, the positioning of poor women as common-sense solutions to development, for example, how women are more fortuitous in collecting water fees-are counterproductive to empowering women. Ray (2016) argues that it is the state's role not only to provide basic human needs, but equally to protect its citizens and their environmental resources. This calls for reasonable investments in water, sanitation and other basic services which, while often considered "mundane investments are in fact the backbone of a decent quality of life, and yet they remain significantly under-invested in, relative to the global need" (ibid; 2). It is precisely because "systemic issues in the world economy"-including what counts for work and how it can become decent, are overlooked - and because of the fact that women's lives and well-being and empowerment cannot be compartmentalised, that meaningful "empowerment looks unthinkably impractical and ideological" (Fukuda-Parr, 2015; 101).

To conclude, doing this research made us feel dismally dispirited by the fact that, while deep, systemic fault lines of complex inequalities by gender through institutionalized power and politics, exclusion and inequality remain intractable, we and others will continue to "do" more research on the lives of poor women in Bangladesh and elsewhere. Unfortunately, as we know well from having "done" research on women and water for a long time, such research achieves little other than meeting rhetorical and politicized science goals of producing knowledge. Despite our entanglement in the politics and rhetoric of research, gender and water, we conclude here that poor women cannot be targeted and made responsible for transforming a deeply unequal world. Disrupting pervasive, entrenched inequalities by gender will require addressing the root causes of inequality and transforming unequal power relations. This includes transformations in policies, interventions, investments, innovations and the drivers of these change processes, that is: addressing the very political economy of development. 
Acknowledgements The design for this research emerged out of a scoping study that was supported by the project "Climate Policy, Conflicts and Cooperation in Peri-Urban South Asia: Towards Resilient and Water Secure Communities" in the framework of the programme Conflict and Cooperation in the Management of Climate Change (CCMCC) funded by NWO (Netherlands Organisation for Scientific Research) and DFID (UK Department For International Development). The research findings presented here in this chapter are from the REACH programme funded by UK Aid from the UK Department for International Development (DFID) for the benefit of developing countries (Aries Code 201880). However, the views expressed and information contained in it are not necessarily those of or endorsed by DFID, which can accept no responsibility for such views or information or for any reliance placed on them. We acknowledge with deep gratitude all the people we met and interacted with in Bhadam and most of all, the women who work in the RMG factories-for giving their time and sharing their experiences without which this paper would not be possible to write.

\section{References}

Asian Development Bank. (2017). The Dhaka water services turnaround: How Dhaka is connecting slums, saving water, raising revenues, and becoming one of South Asia's best public water utilities. Asian Development Bank.

Chant, S. (1999). Women-headed households: Global orthodoxies and grassroots realities. In H. Afshar \& S. Barrientos (Eds.), Women, globalization and fragmentation in the developing world (pp. 99-130). Macmillan.

Chant, S. (2016). Women, girls, and world poverty: Empowerment, equality or essentialism? International Development Planning Review, 38(1), 1-24.

CPD. (2018). Declining female participation in RMG sector: CPD Study, 7 May 2018. Available at: https://cpd.org.bd/declining-female-participation-in-rmg-sector-cpd-study/

Escobar, A. (2007). Worlds and knowledges otherwise: The Latin American modernity/coloniality research program. Journal of Cultural Studies, 21(2-3), 179-210.

Escobar, A. (2015). Degrowth, postdevelopment, and transitions: A preliminary conversation. Sustainability Science, 10(3), 451-462.

Escobar, A. (2016). Thinking-feeling with the earth: Territorial struggles and the ontological dimension of the epistemologies of the South. Revista de Antropología Iberoamericana, $11(1), 11-32$.

Feldman, S. (2009). Historicizing garment manufacturing in Bangladesh: Gender, generation, and new regulatory regimes. Journal of International Women's Studies, 11(1), 268-288.

Fukuda-Parr, S. (2015). Chapter 4: Food security as if gender equality and sustainability mattered. In M. Leach (Ed.), Gender equality and sustainability. Routledge.

Geertz, C. (1998). Deep hanging out. The New York review of books, 45(16), 69.

Heath, R. \& Mushfiq Mobarak, A. (2014, September, 10). Manufacturing growth and the lives of Bangladeshi women (Research briefs in economic policy). Cato Institute.

Heath, R., \& Mushfiq Mobarak, A. (2015). Manufacturing growth and the lives of Bangladeshi women. Journal of Development Economics, 115, 1-15.

Hossain, L., \& Khan, M. S. (2017). Blue and grey water footprint assessment of textile industries of Bangladesh. Conference Paper: International Conference on Chemical Engineering. BUET, Dhaka, December 2017.

Hossain, N. (2012). Women's empowerment revisited: From individual to collective power among the export sector workers of Bangladesh (IDS working paper, 389). IDC.

Hossain, A., Maddow-Zimet, I., Ingerick, M., Ullah Bhuiyan, H., Vlassoff, M., \& Singh, S. (2017). Access to and quality of menstrual regulation and postabortion care in Bangladesh: Evidence from a survey of health facilities. Guttmacher Institute. 
International Labour Organization, Organization for Economic Cooperation and Development World Bank Group International Monetary Fund. (2016). Promote decent work. Shanghai, China: 27-29 April, 2016.

Joshi, D., Fawcett, B., \& Mannan, F. (2011). Health, hygiene and appropriate sanitation: Experiences and perceptions of the urban poor. Environment \& Urbanization, 23(1), 91-111.

Kabeer, N. (1999). The conditions and consequences of choice: Reflections on the measurement of women's empowerment (Discussion paper no. 108). United Nations Research Institute for Social Development (UNRISD).

Kabeer, N. (2000). The power to choose: Bangladeshi women and labor market decisions in London and Dhaka. Verso.

Kabeer, N. (2001). Reflection on the measurement of women's empowerment (SIDA studies no. 3.: Discussing women's empowerment: Theory and practice). SIDA.

Kabeer, N., \& Mahmud, S. (2004a). Rags, riches and women workers: Export-oriented garment manufacturing in Bangladesh. In Chains of fortune: Linking women producers and workers with global markets. Commonwealth Secretariat.

Kabeer, N., \& Mahmud, S. (2004b). Globalization, gender and poverty: Bangladeshi women workers in export and local markets. Journal of International Development, 16(1), 93-109.

Mies, M. (1986). Patriarchy and accumulation on a world scale: Women in the international division of labour. Zed Books.

Ministry of Water Resources. (1999). National water policy. Government of Bangladesh, Ministry of Water Resources.

Nussbaum, M. (2000). Women and human development: The capabilities approach. Cambridge University Press.

Palmer, C. (2001). Ethnography: A research method in practice. International Journal of Tourism Research, 3(4), 301-312.

Pearson, R. (2007). Reassessing paid work and women's empowerment: Lessons from the global economy. In A. Cornwall, E. Harrison, \& A. Whitehead (Eds.), Feminisms in development (pp. 201-213). Zubaan.

Rahman, M. H., \& Siddiqui, S. A. (2015). Female RMG worker: Economic contribution in Bangladesh. International Journal of Scientific and Research Publications, 5(9), 1-9.

Ray, I. (2016). Investing in gender-equal sustainable development (United Nations women discussion paper) (p. 23). UN Women.

Sakamoto, M., Ahmed, T., Begum, S., \& Huq, H. (2019). Water pollution and the textile industry in Bangladesh: Flawed corporate practices or restrictive opportunities? Sustainability, 11(7), 2-14.

Sharma, J., Parthasarathy, K. S., \& Dwivedi, A. (2007). Examining self-help groups empowerment, poverty alleviation, education: A qualitative study. Nirantar.

Souplet-Wilson, S. (2014). Made in Bangladesh: A critical analysis of the empowerment dynamics related to female workers in the Bangladeshi ready-made garment sector. Journal of Politics and International Studies, 11, 359-394.

Sultana, F., Mohanty, C. T., \& Miraglia, S. (2013). Gender justice and public water for all: Insights from Dhaka, Bangladesh. Municipal Services Project (MSP) Occasional Paper, 18, 1-24.

The Dhaka Tribune: WEF: "Bangladesh most gender-equal country in South Asia". https://www. dhakatribune.com/bangladesh/development/2018/12/19/bangladesh-one-of-the-most-genderequal-country-in-s-asia (19.12.2018).

Transnational Institute and Corporate Europe Observatory. (2004). Reclaiming public water! Participatory alternatives to privatization (Water justice project series 2004/7). Transnational Institute.

UN Women. (2017). Annual report 2016-2017. United Nations.

Wakeford, T., \& Rodriquez, J. S. (2018). Participatory action research: Towards a more fruitful knowledge. In K. Facer \& K. Dunleavy (Eds.), Connected (Communities foundation series). University of Bristol/AHRC Connected Communities Programme. 
World Bank. (2008). Whispers to voices: Gender and social transformation in Bangladesh (Bangladesh development series; No. 22).

World Bank. (2012). World development report 2012: Gender equality and development. World Bank.

World Bank. (2017a). South Asia economic focus, fall 2017: Growth out of the blue. World Bank. World Bank. (2017b). In Bangladesh, Empowering and Employing Women in the Garments

Sector, February 7, 2017. https://www.worldbank.org/en/news/feature/2017/02/07/ in-bangladesh-empowering-and-employing-women-in-the-garments-sector

World Economic Forum. (2018, 2019, 2020), The global gender gap report. World Economic Forum.

Open Access This chapter is licensed under the terms of the Creative Commons Attribution 4.0 International License (http://creativecommons.org/licenses/by/4.0/), which permits use, sharing, adaptation, distribution and reproduction in any medium or format, as long as you give appropriate credit to the original author(s) and the source, provide a link to the Creative Commons license and indicate if changes were made.

The images or other third party material in this chapter are included in the chapter's Creative Commons license, unless indicated otherwise in a credit line to the material. If material is not included in the chapter's Creative Commons license and your intended use is not permitted by statutory regulation or exceeds the permitted use, you will need to obtain permission directly from the copyright holder.

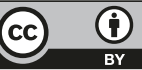

